\title{
An Exploration of the Role of Religion and Spirituality in the Treatment and Recovery of Patients With Eating Disorders
}

\author{
P. Scott Richards \\ Brigham Young University - Provo, pscottrichards@gmail.com \\ Michael E. Berrett \\ Center for Change \\ Carrie L. Caoili \\ Brigham Young University - Provo \\ Sabree A. Crowton \\ Brigham Young University - Provo

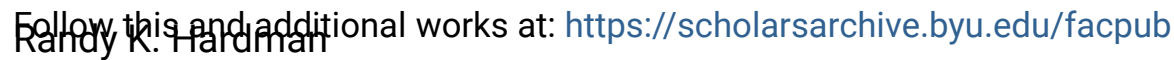

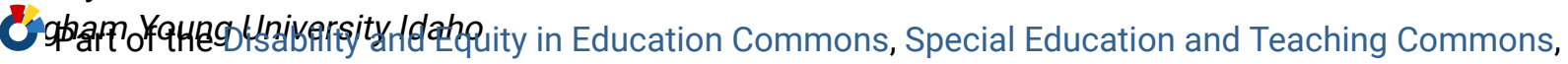 \\ and the Student Counseling and Personnel Services Commons \\ See next page for additional authors \\ Original Publication Citation \\ Richards, P. S., Caoili, C. C., Crowton, S. A., Berrett, M. E., Randy K. Hardman, R. K., Jackson, R. N., \\ \& Sanders, P. W. (2018). An exploration of the role of religion and spirituality in the treatment and \\ recovery of patients with eating disorders. Spirituality in Clinical Practice.
}

\section{BYU ScholarsArchive Citation}

Richards, P. Scott; Berrett, Michael E.; Caoili, Carrie L.; Crowton, Sabree A.; Hardman, Randy K.; Jackson, Russell N.; and Sanders, Peter W., "An Exploration of the Role of Religion and Spirituality in the Treatment and Recovery of Patients With Eating Disorders" (2018). Faculty Publications. 3840.

https://scholarsarchive. byu.edu/facpub/3840

This Peer-Reviewed Article is brought to you for free and open access by BYU ScholarsArchive. It has been accepted for inclusion in Faculty Publications by an authorized administrator of BYU ScholarsArchive. For more information, please contact ellen_amatangelo@byu.edu. 


\section{Authors}

P. Scott Richards, Michael E. Berrett, Carrie L. Caoili, Sabree A. Crowton, Randy K. Hardman, Russell N. Jackson, and Peter W. Sanders

This peer-reviewed article is available at BYU ScholarsArchive: https://scholarsarchive.byu.edu/facpub/3840 


\title{
An Exploration of the Role of Religion and Spirituality in the Treatment and Recovery of Patients With Eating Disorders
}

\author{
P. Scott Richards, Carrie L. Caoili, \\ and Sabree A. Crowton \\ Brigham Young University, Provo, Utah
}

\author{
Michael E. Berrett \\ Center for Change, Orem, Utah
}

\author{
Randy K. Hardman \\ Brigham Young University, Rexburg, Idaho
}

\author{
Russell N. Jackson and Peter W. Sanders \\ Brigham Young University, Provo, Utah
}

\begin{abstract}
This article reports two qualitative studies that explored how religion and spirituality $(\mathrm{R} / \mathrm{S})$ influenced the treatment and recovery process of patients with eating disorder. In Study 1 and Study 2, a total of 83 women who had successfully completed treatment at an inpatient eating disorder treatment center responded to open-ended survey questions about the role of R/S in their recovery. Twelve of the women in Study 2 participated in follow-up phone interviews. Qualitative analysis of survey responses and interview transcripts indicated that although many women believed R/S contributed to the development and maintenance of their eating disorder, most of them also felt it was indispensable to their recovery. Several women believed R/S did not influence or negatively influenced their recovery. The findings from these qualitative studies indicate that some patients with eating disorders who have completed treatment believe that $\mathrm{R} / \mathrm{S}$ can be powerful adjuncts in eating disorder treatment. The findings also provide rich insight into how R/S may assist in treatment and recovery.
\end{abstract}

Keywords: eating disorder, spirituality, religion, etiology, recovery

There is growing evidence that religious and spiritual issues play an important role in eating disorder etiology, treatment, and recovery (Richards, Weinberger-Litman, Susov, \& Berrett, 2013). By religion and spirituality (R/S), we mean the "beliefs, practices, experiences, or relationships that are embedded within both nontraditional, secular contexts and established institutional contexts designed to facilitate the sacred search" (Pargament, Mahoney, \& Shafranske, 2013, p. 17). The exact role of R/S issues in eating disorders, however, is unclear mostly because they are often overlooked in research. Given that most Americans affiliate with an organized religion, this seems to be a significant neglect (Pew Research Center, 2015). If researchers are to increase our knowledge of eating disorders and help develop more
P. Scott Richards, Carrie L. Caoili, and Sabree A. Crowton, Department of Counseling Psychology \& Special Education, Brigham Young University, Provo, Utah; Michael E. Berrett, Center for Change, Orem, Utah; Randy K. Hardman, Counseling Center, Brigham Young University, Rexburg, Idaho; Russell N. Jackson and Peter W. Sanders, Department of Counseling Psychology \& Special Education, Brigham Young University, Provo, Utah.

P. Scott Richards and Carrie L. Caoili are co-first authors of this article. This research was supported in part by an internal grant from the David O. McKay School of Education at Brigham Young University. Study 2 in this article is based on a doctoral dissertation by Carrie A. Caoili. Portions of the findings in Study 1 were presented at the annual Academy of Eating Disorder international conference in 2008.

Correspondence concerning this article should be addressed to P. Scott Richards, Department of Counseling Psychology \& Special Education, Brigham Young University, Provo, UT 84604. E-mail: scott_richards@byu .edu 
sensitive treatments, more studies are needed that explore the role of $\mathrm{R} / \mathrm{S}$ in etiology, treatment, and recovery.

Several scholars have provided theoretical explanations of how R/S influences the development and maintenance of eating disorders. For example, Hardman, Berrett, and Richards (2003; see also Richards, Hardman, \& Berrett, 2007) theorized that eating disorder sufferers pursue thinness as the ultimate solution to their pain and problems rather than reaching out to loved ones and God. Emmett (2009) viewed eating disorders from a psychospiritual framework and suggested that they are "stark manifestations of spiritual disharmony" (p. 19). He argued that this disharmony is evident in the absence of purpose, value, engagement, intimacy, and connection in the lives of sufferers. Lelwica (2010) also conceptualized eating disorders as a spiritual issue, theorizing that traditional religion has been replaced by a contemporary "religion of thinness" (p. 37). She asserted that spiritual emptiness not only makes women more susceptible to disordered eating but also perpetuates disordered eating when it is present.

Spangler (2010) hypothesized that there are three religious pathways that can lead to disordered eating, each of which involve the influence of religious doctrines and practices in the development of the disorder. These include viewing the body as carnal, internalizing negative beliefs about the self as sinful, and taking religious dietary practices to the extreme. Grenfell (2006) likewise proposed that religious principles related to the body (e.g., sexual morality, physical and spiritual purity, standards of dress) contribute to body image disturbance and by association disordered eating. Preliminary research has provided some support for the associations between R/S and eating disorders. Based on their review of the empirical literature, Richards et al. (2013) indicated that the existing research permits several tentative conclusions:

(a) Religious rationales may be used to justify anorexic behaviors, (b) religious orientation may be predictive of ED [eating disorder] symptoms, (c) secure attachment to God is negatively associated with ED risk factors, and (d) religious affiliation may predict the severity of ED symptoms. (p. 323)
There is also growing evidence that R/S can potentially serve as a resource, or sometimes as a hindrance, during eating disorder treatment. Several interview and survey studies demonstrate that many recovered women believe their faith and spirituality helped facilitate their healing and recovery (e.g., Garrett, 1996; Hay \& Cho, 2013; Marsden, Karagianni, \& Morgan, 2007; Mitchell, Erlander, Pyle, \& Fletcher, 1990; Rorty, Yager, \& Rossotto, 1993).

Marsden et al. (2007) interviewed 11 patients to explore the relationships between religion and eating disorder treatment. They found that "for patients with strong religious faith, spiritual practice is helpful in recovery" (p. 11). Matusek and Knudson (2009) conducted in-depth interviews with three former patients with eating disorders and concluded that spiritual commitment was a core component of their recovery. In other research, former patients with eating disorders described turning to Higher Power as a part of their recovery (Buser, Parkins, \& Buser, 2014). Some patients in this study, however, preferred to use other resources and believed spirituality would have negatively interfered with eating disorder treatment.

Additional insight into the role of $\mathrm{R} / \mathrm{S}$ in treatment and recovery is found in experimental, correlational, and case studies (Lea, Richards, Sanders, McBride, \& Allen, 2015; Morgan, Marsden, \& Lacey, 2000; Richards, Smith, Berrett, O'Grady, \& Bartz, 2009; Tramontana, 2009). For example, Morgan et al. (2000) described the treatment processes and outcomes of four female patients. Religion helped facilitate recovery for two of the patients, but one patient lost her faith during treatment and another patient resisted psychodynamic therapy because it challenged her religious beliefs. In a randomized trial experiment, Richards, Berrett, Hardman, and Eggett (2006) found that a spiritual group intervention achieved better outcomes relative to cognitive group therapy and group psychoeducational interventions for patients with eating disorders. Smith, Hardman, Richards, and Fischer (2003) also found in a correlational study that "improvements in spiritual well-being during treatment were significantly associated with positive gains in eating attitudes, less body shape concerns, and positive psychological and social functioning" (p. 15).

Despite the growing evidence that religious $\mathrm{R} / \mathrm{S}$ may promote better treatment outcomes, 
research to date does not provide in-depth, clinically relevant insight into how religion may contribute to the development and maintenance of eating disorders, or why spirituality may be important in treatment and recovery. To help address this gap in the research literature, the current article reports the results of two qualitative studies that provide rich, clinically helpful insight into how former patients with eating disorders perceived that $\mathrm{R} / \mathrm{S}$ influenced their eating disorder treatment and recovery.

In Study 1, we explored the following research questions: (a) How do women believe their eating disorder affected their faith and spirituality? (b) How do women believe that their faith and spirituality helped them during and after treatment? (c) What spiritual interventions do women believe were most helpful during treatment? In Study 2, we explored the following research questions: (a) What are the experiences of women whose eating disorder treatment incorporated spirituality? (b) How do women believe spirituality affected their eating disorder? (c) In what ways do women believe their faith and spirituality helped them during treatment and recovery? (d) In what ways do women believe religion may have negatively impacted their treatment and recovery?

\section{Study 1}

In Study 1, we sought to understand how R/S influenced the treatment and recovery of former patients with eating disorders at Center for Change (CFC), a treatment facility for women with eating disorders located in Utah. CFC approaches treatment from a multidimensional, multidisciplinary perspective with an ecumenical (nondenominational) spiritual emphasis (www.centerforchange.com). Typical treatment includes individual, group, family, expressive, experiential, and recreational therapies along with specialty modalities such as yoga, movement, music, art, and recreational therapies. CFC also provides medical and nutrition treatment, an exercise program, psychosocial education classes, a spirituality group, and a 12-step group adapted for women with eating disorders. Evidence-based therapies such as cognitivebehavioral, dialectical behavior, acceptance and commitment, and family-based therapy comprise the foundation of treatment.

\section{Method}

Research design. A thematic analysis approach, similar to the one described by Braun and Clarke (2006), was used to analyze the data. This is a qualitative research design and a variant of grounded theory. Thematic analysis involves the development of themes that represent patterned responses within the data. Each theme "conveys something significant about what the world (or the particular aspect of the world being discussed) means to a person" (McLeod, 2011, p. 145). The experiences of the participants are intended to be captured as best as possible. This method was selected primarily for its versatility and accessibility. It allows for rich description of and unique insight into the data.

Participants. The participants in this study were 36 former patients from CFC. The ages of the participants ranged from 18 to 45 . Fortyeight percent of the participants identified as Latter-Day Saint (LDS or Mormon), 20\% as Protestant, 9\% as Roman Catholic, 3\% as Jewish, and $20 \%$ as nonaffiliated though spiritually oriented. Forty-two percent of the participants were from Utah, $26 \%$ from other Western states, and 32\% from mid-Western and Eastern states. Thirty-five percent of participants had been diagnosed with anorexia nervosa, $40 \%$ with bulimia nervosa, and $25 \%$ with eating disorder not otherwise specified. All participants had successfully completed 60-90 days of inpatient and/or residential treatment at CFC.

Survey. The surveys consisted of openended questions that inquired about the role that faith and spirituality played in the treatment and recovery of the participants, including (a) How did your eating disorder hurt your spirituality and/or relationship with Higher Power? (b) In what ways did your faith and spirituality help you during your treatment and stay at CFC? (c) What role has your spirituality and faith played in the overall progress you have made in recovering from your eating disorder? (d) What did your therapist or other members of the treatment staff at CFC do to assist you in using the resources of your faith and spirituality during treatment?

Data collection. The data was collected after approval and support was obtained from CFC. Approval was also obtained from the Brigham Young University (BYU) Institutional 
Review Board. The study conformed to U.S. Federal Policy for the Protection of Human Subjects. Fifty former patients of CFC, who the treatment staff nominated as having successfully completed treatment, and for whom R/S played a significant positive role in their treatment, were purposively selected and sent openended question surveys in April 2005. Thirtysix of these former patients responded to the survey by June 2005 for a response rate of $72 \%$.

Data analysis. Two undergraduate research assistants and a doctoral student in counseling psychology, all of whom had been trained in qualitative methodology, analyzed the survey question responses. Emergent themes in the responses within each survey question and across questions were identified and categorized. A Ph.D. licensed psychologist, with an expertise in qualitative data analysis, served as an auditor. The auditor reviewed the themes identified by the student researchers to ensure that the themes were supported by the information provided in the surveys by the former patients. In the few cases where the auditor believed there were discrepancies between the way themes were portrayed by the student researchers and the survey data, consensus was sought and achieved by the auditor and student researchers.

\section{Results}

The emergent themes were labeled as (a) eating disorder undermined spirituality; (b) recovery of spirituality facilitated treatment and recovery from eating disorders; and (c) treatment staff appropriately supported the spiritual beliefs of patients during treatment and recovery. In addition, three to five subthemes emerging within each of the larger themes were identified. A list of the themes and subthemes are summarized below and are presented in Table 1 with illustrative quotes.

Theme 1: Eating disorder undermined spirituality. One of the most prominent themes that emerged from the survey responses was the centrality of the eating disorder in the lives of the participants, to the detriment of their spirituality. Participants reported that their eating disorder (a) displaced and in some cases replaced God or their Higher Power; (b) injured their sense of spiritual identity and worth; and (c) injured their relationship with Higher Power.

Theme 2: Recovery of spirituality facilitated treatment and recovery from eating disorders. A second significant theme was how spirituality had directly impacted the treatment and recovery of participants by (a) expanding their sense of identity; (b) improving their relationship with others including Higher Power; (c) helping them experience feelings of forgiveness; (d) facilitating their healing; and (e) giving them a sense of perspective, meaning, and hope.

Theme 3: Treatment staff supported the spiritual beliefs of patients during treatment. The last theme of importance concerned how the treatment staff supported and provided a safe atmosphere in which patients could explore and utilize their spiritual beliefs and practices to benefit recovery by (a) encouraging patients to be congruent with their spiritual beliefs and accepted practices; (b) providing opportunities to explore their spirituality; and (c) being open to and providing a space for discussions of spirituality.

\section{Discussion}

Study 1 provided insight into how some women perceived R/S to have affected their treatment and recovery from an eating disorder. For many of the participants, disordered eating impaired their spirituality, including their relationship with Higher Power and themselves. Many patients saw turning to Higher Power and their own spiritual beliefs for support and rediscovering their identity as a significant part of the recovery process. These statements are strengthened by research that has found women who feel loved and accepted by God have less disordered eating (Homan \& Boyatzis, 2010; Homan \& Lemmon, 2014). It was also discovered that participants altered religious practices to support eating disorder behaviors, a finding that has been common in interviews with other patients with eating disorders (Boyatzis \& Quinlan, 2008; Brytek-Matera \& Schiltz, 2013; Franczyk, 2014; Graham, Spencer, \& Andersen, 1991; Marsden et al., 2007).

Similar to previous studies, participants attributed the hope, forgiveness, and healing they experienced during treatment to renewed R/S (Marsden et al., 2007). This is consistent with 
Table 1

Themes and Subthemes With Illustrative Quotes Identified From Study 1

\begin{tabular}{|c|c|}
\hline Theme and subtheme & Quote \\
\hline \multicolumn{2}{|c|}{ Theme 1: Eating disorder undermined spirituality } \\
\hline Displaced or in some cases replaced Higher Power & $\begin{array}{l}\text { "In a way, my eating disorder became my God. Rather than turn } \\
\text { to God for strength, I turned to my eating disorder for } \\
\text { control." } \\
\text { "My eating disorder became my God, and was the focus of my } \\
\text { spirituality. At the point when I entered the Center I had } \\
\text { started to pray to my eating disorder. Promising to eat less, } \\
\text { walk more, take more laxatives, and throw up more, praying } \\
\text { that my eating disorder would give me strength to lose the } \\
\text { weight that I need to so that I would be worth something. I } \\
\text { even entered in to covenants with my eating disorder, } \\
\text { promising to lose X-amount of weight by a certain time." }\end{array}$ \\
\hline Injured their sense of spiritual identity and worth & $\begin{array}{l}\text { "My eating disorder robbed me of my self-worth. I felt like } \\
\text { nothing. I could not feel love, for I was unlovable. I could not } \\
\text { give love, for I was incapable." } \\
\text { "I felt like a failure. Doing this to myself made me hate myself } \\
\text { more. I knew that God loved me, but I didn't feel worthy of } \\
\text { His love." } \\
\text { "It made me feel like a fake and so I felt that I misled everyone, } \\
\text { including God, into thinking I was this wonderful person." }\end{array}$ \\
\hline Injured their relationship with Higher Power & $\begin{array}{l}\text { "Because I used my eating disorder to numb my feelings, I was } \\
\text { no longer able to feel a spiritual connection with God and } \\
\text { most of the time I felt utterly alone." } \\
\text { "I felt distant from God, like she/he had abandoned me." } \\
\text { "Having my eating disorder become my God caused a great deal } \\
\text { of problems in my relationship with him. I had replaced God } \\
\text { and now I had no need for him, my life was consumed in a } \\
\text { way of worship that left no room for any God. My eating } \\
\text { disorder did not hurt my relationship with God, it destroyed } \\
\text { it." }\end{array}$ \\
\hline
\end{tabular}

Theme 2: Recovery of spirituality facilitated treatment and recovery from eating disorder

Expanded their sense of identity

Improved their relationship with others including Higher Power

Helped them experience feelings of forgiveness

Facilitated their healing
"Without my spirituality, I would not have been able to separate my identity from the eating disorder. I would not have realized that I am so much more than a body, I am a spirit also. My body is a gift given to me and torturing it and hating it is in no way a show of gratitude."

"Through my faith and hope I have been able to see past those actions and see a person that has hopes and dreams and love; someone that has something to offer the world. I have found an identity as a child of God."

"Spirituality has given me a stronger connection with others. One of the biggest steps in my recovery was and is letting go of control and turning my life and my will over to God. My faith has helped me to put more trust in God and to fully rely on God for strength, courage and guidance."

"Because of my faith I know I can be forgiven and I have a purpose for recovering."

"I had and have to forgive others, God, and myself, and I have to accept that I am still lovable and worthwhile despite my imperfections."

"I think that when I am willing to work on my spirituality I am more willing to commit to recovery." 
Table 1 (continued)

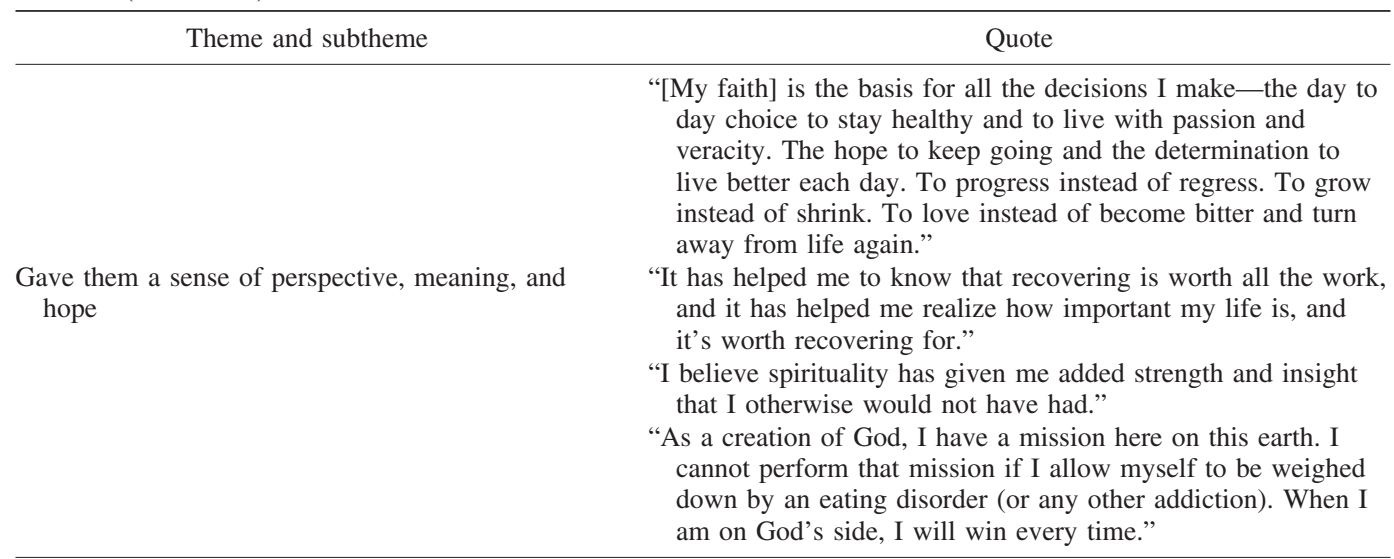

Theme 3: Treatment staff appropriately supported the spiritual beliefs of patients during treatment and recovery

Encouraged patients to be congruent with spiritual beliefs and accepted practices

Provided opportunities to explore their spirituality

Were open to and provided space for discussions of spirituality
"I had all the resources [related to my spiritual values] at my finger tips from books to clergy members [of my faith], to individuals who believed in a Higher Power."

"I took many quiet times in my room reading, pondering, praying and writing in my journal."

The staff "provided opportunities for each person to explore [their own] spirituality and religion-didn't keep it in a totally taboo or 'politically correct' box off to the side."

"I loved 12-step because it was spiritual, but non-denominational-it brought peace."

"During the 12-step group we talked about turning our wills and our lives over to Higher Power and becoming aware of the miracles that were happening in our lives every day."

"As you talk with people it helps to know that you can talk freely about everything and if religion comes out that is fine."

"The most helpful thing my therapist and other staff did to help me use my spirituality was simply [allow it] to be such an integral part of my treatment. I appreciated that they respected my personal beliefs and used those to help me in the personal ways I needed." literature showing that increased spirituality has a positive effect on well-being and in decreasing or lessening eating disorder symptoms such as emotional eating (Boisvert \& Harrell, 2013; Hawks, Goudy, \& Gast, 2003; Watkins, Christie, \& Chally, 2006). Additional research has found that $\mathrm{R} / \mathrm{S}$ in general, and intrinsic religiosity specifically, provides behavioral protection against disordered eating (Boyatzis \& Quinlan, 2008; Castellini et al., 2014; Henderson \& Ellison, 2015; Latzer et al., 2015; Smith, Richards, \& Maglio, 2004; Zhang, 2013).

The other major theme identified was the openness of the treatment staff to spiritual exploration. The 12-step and spirituality groups were described as appreciated adjuncts to evidence-based and best practice models of treatment. These statements emphasize the importance of sensitivity to and acceptance of R/S issues by clinicians (Dell \& Josephson, 2007). Indeed, researchers argue that clinicians and ecclesiastical leaders should help women reexamine gender roles in religious doctrines and find sources of empowerment (Grenfell, 2006; Mitchell et al., 1990; Polinska, 2000). These types of interventions may help in preventing body dissatisfaction and disordered eating among religious women.

\section{Study 2}

Similar to Study 1, the general aim of Study 2 was to explore the experiences of former patients who had received spiritually sensitive eating disorder treatment. Although there is 
support for the inclusion of or sensitivity to spirituality in therapy (Richards \& Bergin, 2005), there are circumstances in which including spirituality may be contraindicated (Miller, 1999; Pargament et al., 2013). This study, therefore, not only sought to explore potentially positive and helpful experiences with spirituality in eating disorder treatment, but also potentially negative or unhelpful experiences. To this end, our research questions were formulated so as to invite participants to share both positive and negative experiences about R/S during treatment and recovery.

In an effort to limit the effect of a potential treatment center bias during the interview process, the primary researcher was a Jewish therapist not affiliated with CFC who did the study for her doctoral dissertation (Caoili, 2015). Through the use of open-ended surveys, followed by phone interviews with some of the survey respondents, the primary researcher sought to obtain narrative accounts of how R/S influenced the treatment and recovery.

\section{Method}

Research design. The data collection and analysis in Study 2 was similar to those followed in Study 1, but the primary researcher was primarily guided by principles of grounded theory (Lincoln \& Guba, 1985; Strauss \& Corbin, 1998), a framework that outlines methods for discovering important themes and linking the themes into models or theories. In brief, the theory-building process inherent in grounded theory methods involves "conceiving or intuiting ideas ... and formulating them into a logical, systematic, and explanatory scheme." (Strauss \& Corbin, 1998, p. 21). The process entails the interplay of collecting data, developing concepts, and suggesting relationships between concepts. Central to this methodological framework is the idea that theories should be tied closely (i.e., "grounded") to the actual data rather than based on unchecked assumptions and interpretations of researchers.

Participants. The participants ages ranged from 13 to $60(M=28)$. Twenty-one $(45 \%)$ identified as LDS, $11 \%$ as Christian, $4 \%$ as Protestant, $2 \%$ as Methodist, $4 \%$ as Roman Catholic, 2\% as Pentecostal, 2\% as Episcopal, $2 \%$ as Seventh-day Adventists, $2 \%$ as Jewish, $2 \%$ as Buddhist, $15 \%$ as spiritual but not reli- giously affiliated, and $9 \%$ as Atheist. Thirty percent were from Utah, 34\% were from other Western states, $11 \%$ were from Southwestern and Midwestern states, 19\% were from Northeastern and Southeastern states, $2 \%$ were from Canada, and 4\% did not report this information. The diagnoses at treatment intake for the participants included anorexia nervosa (32\%), bulimia nervosa $(37 \%)$, and eating disorder not otherwise specified (31\%).

Survey. The open-ended questions below were developed for the survey and interview, with the goal of inviting respondents to share how spirituality had both positively and negatively impacted their treatment and recovery. During the interviews, the researcher was able to explore these questions in greater depth with the participants. The questions were (a) Please tell me a little bit of history about your eating disorder, beginning from when it was at its worst up until recovery and where you are today? (b) Please describe what things helped you the most through your eating disorder and recovery? (c) Please talk about what role has your faith and spirituality played in your treatment and recovery? (d) Please describe any spiritual practices in your recovery that helped with treatment? (e) Can you talk about ways that your faith/religious background may have negatively impacted your eating disorder? (f) Can you talk about ways that your eating disorder may have negatively impacted your faith and spirituality? (g) Can you describe any specific experiences during counseling and therapy that affected your treatment and recovery? (h) What would you tell other girls or women going through a similar experience? (i) Is there anything else about the role of spirituality in treatment and recovery that you would like to share?

Data collection. After receiving approval from the CFC administration and the BYU Institutional Review Board, participants were selected through a careful screening process conducted by the staff at CFC. The staff was asked to identify 65 patients who had successfully completed or were close to successfully completing the treatment program. These patients were emailed an invitation in December 2013, to participate in the study that contained an informed consent document with a link to an online survey about the role of spirituality in their treatment and recovery. Forty-seven women responded to the survey during 
March-June 2014, for a $72.3 \%$ response rate. The primary researcher then selected 12 patients who responded to the online survey to participate in a 30-90-min follow-up interviews.

Of the 47 women who responded to the survey, 12 who viewed religion and spirituality as relevant in positive or negative ways to their treatment and recovery were selected by the primary researcher to participate in a follow-up phone interview. These interviews were conducted between June-August, 2014. Twelve interviews were deemed a sufficient number as the interviewers felt she had reached the point of information saturation or redundancy. Researchers have determined that this is generally the number needed to achieve saturation in cases where the sample is relatively homogeneous (Charmaz, 2014).

Data analysis. After the surveys were returned, and the interviews completed and transcribed, the primary researcher and an auditor (not employed by CFC) independently reviewed the transcripts and developed themes relevant to the research questions based on thematic analysis (Braun \& Clarke, 2006). Comparison between the themes identified by the primary researcher and the auditor revealed high congruence, although a few were altered to bring them into acceptable coherence. These themes are discussed below.

\section{Results}

Regarding religious backgrounds of these 12 interviewees, seven identified as LDS, one as Jewish, one as Catholic, one as Seventh-day Adventists, one as spiritual but not religious, and one as Atheist. Participants were asked to share the story of their eating disorder, and they were asked to expand on the answers they provided to the survey.

Qualitative analysis of the survey responses and interviews revealed three major themes and several subthemes each larger theme. A list of the themes and subthemes with illustrative quotes from participants in Study 2 are presented in Table 2.

Theme 1: Unhealthy spirituality was intertwined with eating disorder development. Some of the women believed that negative aspects of R/S were intertwined with the development and maintenance of their eating disorder. These aspects included (a) negative feelings toward Higher Power; (b) bullying by members in their religious community because of their eating disorder; (c) perfectionism connected to their church or religion; and (d) feelings of shame, guilt, or worthlessness connected to religious views.

Theme 2: Spirituality played a positive, helpful role in treatment and recovery. Many participants believed that spiritual interventions, practices, and experiences facilitated their eating disorder treatment and recovery. It was an important resource for participants in finding meaning and purpose in their struggles. Specific positive aspects highlighted by these participants included: (a) spiritual connection with Higher Power; (b) prayer and prayer books; (c) permission to explore spirituality by the treatment team; and (d) support from religion, religious leaders, and spiritual communities. Other helpful activities regarded as spiritual by the participants included (e) connection with nature; (f) spiritual meditation and mindfulness; (g) assisting others in their recovery; (h) creative work; (i) assertiveness; (j) self-love, and (k) supportive relationships.

Theme 3: Spirituality was not important or helpful in treatment and recovery. A few participants expressed that spirituality would not be relevant for certain patients. An additional subset of participants felt that spirituality had been detrimental or unhelpful during treatment and believed it should not be included in treatment. The experiences of participants included (a) irrelevance of spirituality and (b) a negative relationship with High Power, family/ friends, and treatment team members.

\section{Discussion}

Study 2 extended the results of Study 1 by revealing additional perspectives that some women have about the role of $\mathrm{R} / \mathrm{S}$ in their eating disorder treatment and recovery. First, our qualitative analysis provided evidence that negative or unhealthy beliefs or use of R/S can contribute to the development of eating disorders for some women. Multiple participants in Study 2 used religious principles to rationalize disordered eating behaviors. Religious teachings being used to justify disordered eating and maintain perfectionism standards have been reported in other research (Banks, 1992, 1997; Boyatzis \& Quinlan, 2008; Brytek-Matera \& Schiltz, 2013; 
Table 2

Themes and Subthemes and Illustrative Quotes Identified in Study 2

\begin{tabular}{cc} 
Theme and subtheme & Quote \\
\hline
\end{tabular}

Theme 1: Unhealthy spirituality was intertwined with eating disorder development

Negative feelings toward Higher Power

Bullying by members in their religious community because of their eating disorder

Perfectionism connected to their church or religion

Feelings of shame, guilt, or worthlessness connected to religious views

Theme 2: Spirituality played a positive, helpful role in treatment and recovery

Spiritual connection with Higher Power

Prayer and prayer books relationship I have in my life." darkest moments."
"As I struggled with my eating disorder, I felt somewhat abandoned by God, and the thought of going to synagogue made me panicky. I don't know if it was the feeling of abandonment or just that I was overwhelmed with everything that was going on, but I stopped attending synagogue."

"I had no belief in God anymore. I was done believing that there was, "cause I just figured, everyone kept saying that God was so good. He was this wonderful person and I thought, all these times I've been praying for things to stop or people to quit doing things to me and they weren't stopping. And they just kept going on and so I . . . became completely Atheist, or I considered myself completely Atheist. I wanted nothing to do with any religion, period."

"I had no friends. I got made fun of all the time. There were a lot of girls at my church who kind of made fun of me and they would [prank] me a lot and stuff ... then I had no support group at church, and so I hated going to church. The guys all made fun of me too. There were a lot of comments ... if I was late ... they'd be like, 'Oh, [she's] in the bathroom throwing up her breakfast.' . . . So there were a lot of jokes like that, which kind of made my eating disorder worse for some reason."

"I felt I had to be perfect and if I wasn't, I was a failure. I hated myself because I could never be perfect. I felt like I was being judged by perfect people. I felt like because I was fat, I was a failure and I couldn't do anything right in anyone's eyes. I wanted to do anything to get skinny because it would help me at least seem perfect on the outside."

"With my eating disorder I have always carried a lot of unworthiness, guilt, shame, and a feeling of being worthless."

"My relationship with God is the most important

"My faith and spirituality have played a huge role in recovery because with an eating disorder I feel extremely alone in the mental and physical pain. But I have always known I can turn to . . . my Higher Power and he will always be there even through the

"I had hit a really bad low where I was having extremely negative thoughts. I prayed like I hadn't in a long time, and that night I received an answer to why I was there, that I would be ok, that I was important, and that I could recover. There are many times that I would get down and want to give up, but I know that if I pray often and sincerely ask for help, I will feel that spirit and it will give me the strength to go on." 
Table 2 (continued)

Theme and subtheme
Permission to explore spirituality by the trea
team
Support from religion, religious leaders, and
spiritual communities

Support from religion, re
spiritual communities

Connection with nature

Spiritual meditation and mindfulness

Assisting others in their recovery

Creative work

Assertiveness
Quote

"I was very impressed that my therapist openly declared that they are relying on God and spirituality in their treatment approach. I also thoroughly enjoyed our spirituality group as well."

"My religion has been absolutely essential in recovery. Without God's help, I would still be extremely sick with no motivation to recover. I believe in an afterlife, and that is the SOLE REASON I did not commit suicide when I was deep into my eating disorder. My religious beliefs literally saved my life."

"[My ecclesiastical leader] told me when I was in the hospital that I hadn't done anything wrong. For him to even say that I didn't need to be called to repentance because I hadn't done anything wrong was really nice to hear. It was actually really comforting because then I felt like I could just focus on myself and healing myself instead of worrying about making it right with, you know, my Higher Power."

"I don't pray, but at the same time, I feel like there is power within me that is connected to the power in the universe, or the earth, or something, I don't know, but it [connected] me with my next step sometimes."

"Meditation. Sitting quietly and listening to the deepest parts of myself. There was always something deep inside me that knew the next right step. The only way to hear that was to stop and listen."

"Through yoga and meditation, I found a way to let my own voice direct my decisions and I was able to find strength by opening up to the idea of the energy of the universe, and my connection to it."

"In the Center we had a spirituality group and the very first time, it was in that group actually that I had, that I felt something for the first time in a long time."

"I do believe it was the best thing I could have ever gone through to eventually . . . learn more about myself and to hopefully be an advocate for other girls [who are] going through this."

"I have had the opportunity since I have been discharged from the Center to talk to groups of women and young women in my faith about the things that I learned, and the struggles that I faced are similar to many women in my faith."

"One way that I was able to stay spiritually connected was to journal. I continue to journal at least once a week so I can write all my worries and frustrations down as well as recognizing the blessings in my life."

"I would say [to other patients], 'You need to learn to love yourself,' and that's what I'm trying to do, and I think that's what they all need to learn is that they need to love themselves because God loves them . . . Even though my weight is extremely low, I think I've made great strides in beating the eating disorder this time because I am willing to stand up for myself. I'm willing to say, 'You're not in control of my life.' And so, if I could just tell them, you know, 'Stand up for yourself and know that you are loved for who you are.' They just want to be loved."

(table continues) 
Table 2 (continued)

\begin{tabular}{|c|c|}
\hline Theme and subtheme & Quote \\
\hline Self-love & $\begin{array}{l}\text { "I may not remember every single day, but the acts, the } \\
\text { things that I do, my fight. That is what reminds me } \\
\text { and is proof to me that I love myself and that I have } \\
\text { value and . . . worth. And, I cannot look at someone } \\
\text { and tell them recovery is easy. I've done treatment a } \\
\text { long time and it doesn't matter the amount of time } \\
\text {. . [But] the moment that you decide to do it for } \\
\text { yourself, that's when it sticks." } \\
\text { "That moment when you're able, when you've been fed, } \\
\text { that you're able to think clearly and you're able to see } \\
\text { yourself as a person. . . That moment where you're } \\
\text { able to look at yourself and see someone who has } \\
\text { value, someone with potential. That moment when } \\
\text { you can connect with yourself and realize that, 'You } \\
\text { know what, I love myself.' I may not remember it } \\
\text { every single day, but I know it's the truth." }\end{array}$ \\
\hline Supportive relationships & $\begin{array}{l}\text { "I had several big influences in my life, like I'd say my } \\
\text { parents were a huge influence, my therapist, my last } \\
\text { therapist was a huge influence at the Center, my } \\
\text { husband was a huge influence, and I think my } \\
\text { daughter was the final turning point for me. And, and } \\
\text { so, yeah, I mean since then, I've been doing super } \\
\text { good." }\end{array}$ \\
\hline
\end{tabular}

Theme 3: Spirituality was not important or helpful in treatment and recovery

Irrelevance of spirituality

Negative relationships with God and others
"I think that it's determined on a case by case basis. I think it's important to turn to SOMETHING meaningful outside of your eating disorder. You need to be motivated and feel hopeful about something in life. Whether that's a higher power or not, needs to be decided by the individual."

"I think it's different for everyone. Some things that have really helped me may not work for others."

"I don't think spirituality should be of most importance when recovering or in treatment of an eating disorder. Let's say there is a 'God.' 'God' is not going to fix your eating disorder. Fixing your eating disorder is a choice a person has to make."

"I think there are a lot of bad things that happen . . . in the world in general, when, if God's real, then why would that stuff exist?"

"I am neither religious or spiritual . . . it was not helpful to me in treatment ... sometimes I felt left out."
Franczyk, 2014; Graham et al., 1991; Marsden et al., 2007; Richards et al., 2007). Some participants also mentioned that bullying within their own religious communities prompted or perpetuated their disordered eating. This is consistent with evidence that suggests that peer bullying is associated with poor body image and disturbed eating patterns (Gaskill \& Sanders, 2000).

Second, most theistically oriented participants reported that a renewed connection to Higher Power was imperative to overcoming their eating disorder. This is consistent with the analysis conducted in Study 1 as well as previous research (Richards et al., 2009; Tramontana, 2009). This theme also aligns with literature showing that a secure attachment to God is associated with less disordered eating (Homan \& Boyatzis, 2010; Homan \& Lemmon, 2014). Similar to other studies, participants mentioned that religious resources (i.e., prayer, scripture reading, and religious community) provided comfort during treatment (Jersild, 2001; Richards et al., 2009; Wasson \& Jackson, 2004). The 
apparent benefits from these resources may be explained in part by research indicating that healthy religious coping can provide an alternative to maladaptive eating (Pirutinsky, Rosmarin, \& Holt, 2012). Women with strong R/S beliefs in previous studies have likewise cited prayer, meditation, and scripture study as helping them effectively cope with body image distress (Jacobs-Pilipski, Winzelberg, Wilfley, Bryson, \& Taylor, 2005).

Third, as in other accounts, some participants in Study 2 stated that they did not necessarily oppose $\mathrm{R} / \mathrm{S}$ in treatment, but thought it was ultimately up to personal preference (Buser et al., 2014). Some participants identified practices like meditation, time in nature, creative work, and serving others as meaningful and helpful spiritual interventions in their own treatment and recovery. There was also a minority who believed that religion and spirituality had negatively impacted their treatment. These participants felt left out during group therapy when spiritual topics were discussed because they couldn't relate. These negative experiences are consistent with the reported experience of patients in other research on eating disorders and spirituality (Buser et al., 2014).

\section{Conceptual Model}

A conceptual model is presented in Figure 1 and is intended to summarize the findings from Studies 1 and 2. This model represents the relationship between R/S and eating disorder development, treatment, and recovery. This model adds to previous literature that has theorized about the relationship between R/S and disordered eating (Grenfell, 2006; Hardman et al., 2003; Richards et al., 1997; Spangler, 2010).

On the left side of the figure, eating disorder development and pathology are influenced by decreases in spiritual connection-and vice versa. We define spiritual connection (and disconnection) to mean the quality of a patient's relationship with self, others, and her Higher Power. The arrows go in both directions between spiritual disconnection and eating disorder pathology to suggest the reciprocal impact they have on each other.

Several participants stated that a poor or disconnected sense of their own spiritual identity and worth increased their vulnerability in the development of their eating disorder. This spiritual vulnerability included a negative or less connected relationship with Higher Power, their religious community, family/friends, and themselves. For other participants, the development of their eating disorder damaged their spiritual identity and worth. As their connection to the illness increased, their connection to spiritual sources including themselves decreased. Spiritual connection was often inadvertently sacrificed in the drive to maintain disordered eating. Thus, for some patients, disconnection to spiritual sources may have contributed to the development and maintenance of their eating disorder.

In the middle of the figure, a box was placed to illustrate that spiritually integrated treatment helps break the unhealthy eating disorder cycle by encouraging patients to reconnect with their spirituality, including their relationships with self, others, and Higher Power. Although it is

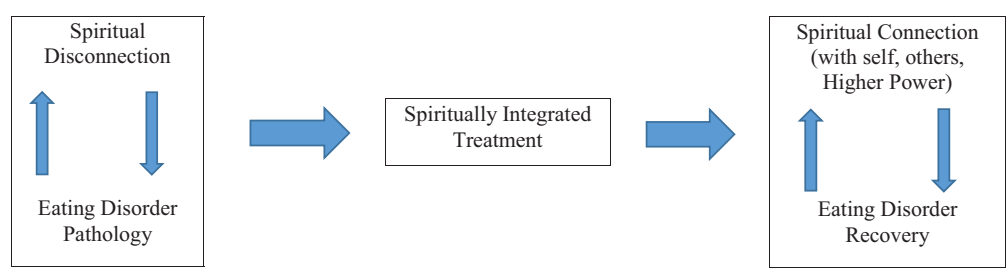


beyond the scope of this article to do so, various types of spiritually integrated, or spiritually sensitive, treatment have been described in the professional literature (e.g., Berrett, Hardman, \& Richards, 2010; Emmett, 2009; Johnston, 1996; Johnson \& Sansone, 1993; Lelwica, 1999, 2010; Manley \& Leichner, 2003; Maine \& Kelly, 2005; Richards et al., 2007; Ross, 2007, 2009). Spiritually integrated treatment approaches can help patients reconnect with their spirituality and challenge the false ideas and pursuits of the eating disorder (Richards et al., 2007), which enables them to begin the healthy cycle of eating disorder recovery.

On the right side of the figure, it can be seen that eating disorder recovery is influenced by spiritual connections - and vice versa. Many participants in our studies believed that spiritual reconnection was essential to their recovery. Some stated that their Higher Power was a source of strength and support throughout treatment. Spiritual groups, religious practices, and connection to the community of their religious faith were some of the activities cited as helpful by the participants. For some, connection with their bodies through yoga, connection with nature, mindfulness, and meditation were helpful practices and increased spiritual connection and recovery. The attention shift from disordered eating to healthy living allowed patients to rediscover areas of their lives that had been neglected during their disorder. For many patients, spirituality became more of a focus in their personal lives. Their renewed spirituality facilitated eating disorder recovery. The cycle of recovery promotes healing and growth and makes complete recovery possible.

The relationship between spiritual connection and eating disorder treatment development, maintenance, treatment, and recovery is contingent to some degree upon the personal and individual importance of spirituality to the individual. Some participants mentioned benefiting from spiritual connection despite not previously having strong R/S beliefs. However, a few patients commented that an emphasis on spirituality was not helpful to them during treatment.

\section{Limitations and Strengths of the Studies}

Study 1 and Study 2 did not include the eating disorder illnesses of binge eating disorder or avoidant/restrictive intake disorder. The samples from each study also consisted only of female respondents. In addition, although a number of different religions were represented, approximately $50 \%$ of the participants were members of the LDS church. Thus, our samples do not represent the religious demographics of the general population. It may well be that individuals across a broader religious and spiritual spectrum would have different experiences with spiritually integrated eating disorder treatments.

Finally, data for Study 1 was collected over 10 years ago and so questions might be raised about whether its findings are dated. However, data for Study 2 was collected more recently (in 2014). Given that the findings from Study 2 largely repeated and confirmed the themes from Study 1, this provides some evidence and reassurance that spirituality continues to play an important role in treatment and recovery for many patients in contemporary American society.

The studies also have a number of strengths. Through the use of open-ended surveys, the researchers were able to include a sizable number of former patients and collect in-depth information on their perspectives and experiences. These studies were also significant in that they targeted patients with a range of diagnoses including anorexia nervosa, bulimia nervosa, and eating disorder not otherwise specified. Furthermore, the participants represented a number of different religions, ages, ethnicities, and socioeconomic backgrounds. Perhaps most importantly, these studies provided rich information about how patients view R/S as connected to the development, treatment, and recovery from their eating disorder.

\section{General Discussion}

These two qualitative studies provide valuable insight into how eating disorder onset, maintenance, treatment, and recovery can be impacted by R/S. The analysis from both studies revealed that a significant portion of women believed R/S is an indispensable support in eating disorder treatment. Results from Study 2 were consistent with Study 1 but added additional perspectives of how R/S can negatively impact women during the development and treatment of their eating disorder. Together, these studies provide preliminary support that 
appropriate and sensitive use of spiritual themes and interventions during eating disorder treatment can lead to positive and profound effects for many patients.

We believe that the findings from these two studies will prove useful to practitioners and researchers who wish to further explore the role of religion and spirituality in eating disorder treatment and recovery. Study 1 and 2 are of high clinical relevance and may help clinicians more fully understand how religious patients may use faith-based religious doctrines or principles against themselves in the maintenance of illness or for their own benefit in the service of recovery from illness. It is also important that while many patients have benefited from spiritual and/or religious beliefs, the same has hurt some. By examining both the positive and negative role that R/S play in eating disorders, it is hoped that clinicians can develop greater sensitivity to the many possible meanings and implications of spiritual emphasis or interventions during treatment. Although it is clear that pressure for inclusion of spirituality in treatment is unhelpful, permission to include it can be helpful. Future research should continue to examine the role of R/S in the treatment of eating disorders and the potential use of spiritually oriented treatments to facilitate recovery.

\section{References}

Banks, C. G. (1992). "Culture" in culture-bound syndromes: The case of anorexia nervosa. Social Science \& Medicine, 34, 867-884. http://dx.doi.org/ 10.1016/0277-9536(92)90256-P

Banks, C. G. (1997). The imaginative use of religious symbols in subjective experiences of anorexia nervosa. Psychoanalytic Review, 84, 227-236.

Berrett, M. E., Hardman, R. K., \& Richards, P. S. (2010). The role of spirituality in eating disorder treatment and recovery. In M. Maine, B. H. McGilley, \& D. W. Bunnell (Eds.), Special issues in the treatment of eating disorders: Bridging the gaps (pp. 367-385). Maryland Heights, MO: Elsevier. http://dx.doi.org/10.1016/B978-0-12-375668-8 .10022-1

Boisvert, J. A., \& Harrell, W. A. (2013). The impact of spirituality on eating disorder symptomatology in ethnically diverse Canadian women. International Journal of Social Psychiatry, 59, 729-738. http://dx.doi.org/10.1177/0020764012453816

Boyatzis, C. J., \& Quinlan, K. B. (2008). Women's body image, disordered eating, and religion: $\mathrm{A}$ critical review of the literature. Research in the Social Scientific Study of Religion, 19, 183-208.

Braun, V., \& Clarke, V. (2006). Using thematic analysis in psychology. Qualitative Research in Psychology, 3, 77-101. http://dx.doi.org/10.1191/ 1478088706qp063oa

Brytek-Matera, A., \& Schiltz, L. (2013). Comparative structural study of the configuration of coping strategies among female patients with eating disorders and a non-clinical control group. Psychiatria Danubina, 25, 359-365.

Buser, J. K., Parkins, R. A., \& Buser, T. J. (2014). Thematic analysis of the intersection of spirituality and eating disorder symptoms. Journal of Addictions \& Offender Counseling, 35, 97-113. http:// dx.doi.org/10.1002/j.2161-1874.2014.00029.x

Caoili, C. (2015). The role of spirituality in treatment and recovery from eating disorders. All Theses and Dissertations. Paper 5484. Retrieved from http:// scholarsarchive.byu.edu/etd

Castellini, G., Zagaglioni, A., Godini, L., Monami, F., Dini, C., Faravelli, C., \& Ricca, V. (2014). Religion orientations and eating disorders. Rivista di Psichiatria, 49, 140-144.

Charmaz, K. (2014). Constructing grounded theory. (2nd ed.). Thousand Oaks, CA: SAGE Publications.

Dell, M. L., \& Josephson, A. M. (2007). Religious and spiritual factors in childhood and adolescent eating disorders and obesity. Southern Medical Journal, 100, 628-632. http://dx.doi.org/10.1097/ SMJ.0b013e31805fe689

Emmett, S. (2009). Wholeness and holiness: A psychospiritual perspective. In M. Maine, W. N. Davis, \& J. Shure (Eds.), Effective clinical practice in the treatment of eating disorders: The heart of the matter (pp. 19-33). New York, NY: Routledge.

Franczyk, D. (2014). The role of spirituality/religion as a coping mechanism during treatment for disordered eating. Dissertation Abstracts International Section A: Humanities and Social Sciences, $76(2-\mathrm{A})(\mathrm{E})$.

Garrett, C. J. (1996). Recovery from anorexia nervosa: A Durkheimian interpretation. Social Science \& Medicine, 43, 1489-1506. http://dx.doi .org/10.1016/0277-9536(96)00088-3

Gaskill, D., \& Sanders, F. (2000). The encultured body: Policy implications for healthy body image and disordered eating behaviours. Brisbane, Australia: Queensland University of Technology.

Graham, M. A., Spencer, W., \& Andersen, A. E. (1991). Altered religious practice in patients with eating disorders. International Journal of Eating Disorders, 10, 239-243. http://dx.doi .org/10.1002/1098-108X(199103)10:2<239:: AID-EAT2260100215>3.0.CO;2-4

Grenfell, J. W. (2006). Religion and eating disorders: Towards understanding a neglected perspective. 
Feminist Theology: The Journal of the Britain \& Ireland School of Feminist Theology, 14, 367-387. http://dx.doi.org/10.1177/0966735006063775

Hardman, R. K., Berrett, M. E., \& Richards, P. S. (2003). Spirituality and ten false beliefs and pursuits of women with eating disorders: Implications for counselors. Counseling and Values, 48, 67-78. http://dx.doi.org/10.1002/j.2161-007X .2003.tb00276.x

Hawks, S. R., Goudy, M. B., \& Gast, J. A. (2003). Emotional eating and spiritual well-being: A possible connection? American Journal of Health Education, 34, 30-33. http://dx.doi.org/10.1080/ 19325037.2003.10603522

Hay, P. J., \& Cho, K. (2013). A qualitative exploration of influences on the process of recovery from personal written accounts of people with anorexia nervosa. Women \& Health, 53, 730-740. http://dx .doi.org/10.1080/03630242.2013.821694

Henderson, A. K., \& Ellison, C. G. (2015). My body is a temple: Eating disturbances, religious involvement, and mental health among young adult women. Journal of Religion and Health, 54, 954-976. http://dx.doi.org/10.1007/s10943-014-9838-y

Homan, K. J., \& Boyatzis, C. J. (2010). The protective role of attachment to God against eating disorder risk factors: Concurrent and prospective evidence. Eating Disorders, 18, 239-258. http://dx .doi.org/10.1080/10640261003719534

Homan, K. J., \& Lemmon, V. A. (2014). Attachment to God and eating disorder tendencies: The mediating role of social comparison. Psychology of Religion and Spirituality, 6, 349-357. http://dx.doi .org/10.1037/a0036776

Jacobs-Pilipski, M. J., Winzelberg, A., Wilfley, D. E., Bryson, S. W., \& Taylor, C. B. (2005). Spirituality among young women at risk for eating disorders. Eating Behaviors, 6, 293-300. http://dx .doi.org/10.1016/j.eatbeh.2005.03.003

Jersild, A. (2001). Field mice and mustard seeds: Approaching spirituality as a therapeutic tool. Eating Disorders, 9, 267-274.

Johnson, C. L., \& Sansone, R. A. (1993). Integrating the twelve-step approach with traditional psychotherapy for the treatment of eating disorders. International Journal of Eating Disorders, 14, 121-134. http://dx .doi.org/10.1002/1098-108X(199309)14:2<121:: AID-EAT2260140202>3.0.CO;2-N

Johnston, A. (1996). Eating in the light of the moon: How women can transform their relationships with food through myths, metaphors and storytelling. Carlsbad, CA: Gurze Books.

Latzer, Y., Weinberger-Litman, S. L., Gerson, B., Rosch, A., Mischel, R., Hinden, T., . . Silver, J. (2015). Negative religious coping predicts disordered eating pathology among Orthodox Jewish adolescent girls. Journal of Religion and Health,
54, 1760-1771. http://dx.doi.org/10.1007/s10943014-9927-y

Lea, T., Richards, P. S., Sanders, P. W., McBride, J. A., \& Allen, G. E. K. (2015). Spiritual pathways to healing and recovery: An intensive single- $N$ study of an eating disorder patient. Spirituality in Clinical Practice, 2, 191-201. http://dx.doi.org/10 $.1037 / \mathrm{scp} 0000085$

Lelwica, M. M. (1999). Starving for salvation. New York, NY: Oxford University Press.

Lelwica, M. M. (2010). The religion of thinness. Carlsbad, CA: Gurze Books.

Lincoln, Y. S., \& Guba, E. G. (1985). Naturalistic inquiry. Newbury Park, CA: Sage.

Maine, M., \& Kelly, J. (2005). The body myth: Adult women and the pressure to be perfect. Hoboken, NJ: Wiley.

Manley, R. S., \& Leichner, P. (2003). Anguish and despair in adolescents with eating disordershelping to manage suicidal ideation and impulses. Crisis, 24, 32-36. http://dx.doi.org/10.1027//02275910.24.1.32

Marsden, P., Karagianni, E., \& Morgan, J. F. (2007). Spirituality and clinical care in eating disorders: A qualitative study. International Journal of Eating Disorders, 40, 7-12. http://dx.doi.org/10.1002/eat .20333

Matusek, J. A., \& Knudson, R. M. (2009). Rethinking recovery from eating disorders: Spiritual and political dimensions. Qualitative Health Research, 19, 697-707. http://dx.doi.org/10.1177/10497 32309334077

McLeod, J. (2011). Qualitative research in counseling and psychotherapy (2nd ed.). London, UK: Sage Publishers.

Miller, W. (Ed.). (1999). Integrating spirituality into treatment: Resources for practitioners. Washington, DC: American Psychological Association. http://dx.doi.org/10.1037/10327-000

Mitchell, J. E., Erlander, R. M., Pyle, R. L., \& Fletcher, L. A. (1990). Eating disorders, religious practices and pastoral counseling. International Journal of Eating Disorders, 9, 589-593. http://dx .doi.org/10.1002/1098-108X(199009)9:5<589:: AID-EAT2260090517>3.0.CO;2-Z

Morgan, J. F., Marsden, P., \& Lacey, J. H. (2000). "Spiritual starvation?": A case series concerning christianity and eating disorders. International Journal of Eating Disorders, 28, 476-480. http://dx.doi .org/10.1002/1098-108X(200012)28:4<476::AIDEAT19>3.0.CO;2-T

Pargament, K. I., Mahoney, A., \& Shafranske, E. P. (Eds.). (2013). APA handbook of psychology, religion, and spirituality: Vol. 2. An applied psychology of religion and spirituality. Washington, DC: American Psychological Association.

Pew Research Center. (2015). America's changing religious landscape. Retrieved from http://www 
.pewforum.org/2015/05/12/americas-changingreligious-landscape/

Pirutinsky, S., Rosmarin, D. H., \& Holt, C. L. (2012). Religious coping moderates the relationship between emotional functioning and obesity. Health Psychology, 31, 394-397. http://dx.doi.org/10 .1037/a0026665

Polinska, W. (2000). Bodies under siege: Eating disorders and self-mutilation among women. Journal of the American Academy of Religion, 68, 569590. http://dx.doi.org/10.1093/jaarel/68.3.569

Richards, P. S., \& Bergin, A. E. (2005). A spiritual strategy for counseling and psychotherapy (2nd ed.). Washington, DC: American Psychological Association. http://dx.doi.org/10.1037/11214-000

Richards, P. S., Berrett, M. E., Hardman, R. K., \& Eggett, D. L. (2006). Comparative efficacy of spirituality, cognitive, and emotional support groups for treating eating disorder inpatients. Eating Disorders: The Journal of Treatment \& Prevention, 14, 401-415. http://dx.doi.org/10.1080/10640 260600952548

Richards, P. S., Hardman, R. K., \& Berrett, M. E. (2007). Spiritual approaches in the treatment of women with eating disorders. Washington, DC: American Psychological Association. http://dx.doi .org/10.1037/11489-000

Richards, P. S., Hardman, R. K., Frost, H. A., Berrett, M. E., Clark-Sly, J. B., \& Anderson, D. K. (1997). Spiritual issues and interventions in the treatment of patients with eating disorders. Eating Disorders: The Journal of Treatment \& Prevention, 5, 261-279. http://dx.doi.org/10.1080/10640 269708249234

Richards, P. S., Smith, M. H., Berrett, M. E., O'Grady, K. A., \& Bartz, J. D. (2009). A theistic spiritual treatment for women with eating disorders. Journal of Clinical Psychology, 65, 172-184. http://dx.doi.org/10.1002/jclp.20564

Richards, P. S., Weinberger-Litman, S. L., Susov, S., \& Berrett, M. E. (2013). Religiousness and spirituality in the etiology and treatment of eating disorders. In K. I. Pargament, A. Mahoney, \& E. P. Shafranske (Eds.), APA handbook of psychology, religion, and spirituality: Vol. 2. An applied psychology of religion and spirituality (pp. 319-333). Washington, DC: American Psychological Association. http://dx.doi.org/10.1037/14046-016

Rorty, M., Yager, J., \& Rossotto, E. (1993). Why and how do women recover from bulimia nervosa? The subjective appraisals of forty women recovered for a year or more. International Journal of Eating Disor- ders, 14, 249-260. http://dx.doi.org/10.1002/1098108X(199311)14:3<249::AID-EAT2260140303>3 .0.CO;2-O

Ross, C. C. (2007). Healing body, mind and spirit: An integrative medicine approach to the treatment of eating disorders. Denver, CO: Outskirts Press.

Ross, C. C. (2009). The binge eating and compulsive overeating workbook: An integrated approach to overcoming disordered eating. Oakland, CA: New Harbinger Publications.

Smith, F. T., Hardman, R. K., Richards, P. S., \& Fischer, L. (2003). Intrinsic religiousness and spiritual well-being as predictors of treatment outcome among women with eating disorders. Eating Disorders, 11, 15-26. http://dx.doi.org/10.1080/ 10640260390167456-2199

Smith, M. H., Richards, P. S., \& Maglio, C. J. (2004). Examining the relationship between religious orientation and eating disturbances. Eating Behaviors, 5, 171-180. http://dx.doi.org/10.1016/S14710153(03)00064-3

Spangler, D. L. (2010). Heavenly bodies: Religious issues in cognitive behavioral treatment of eating disorders. Cognitive and Behavioral Practice, 17, 358-370. http://dx.doi.org/10.1016/j.cbpra.2009 .05 .004

Strauss, A., \& Corbin, J. (1998). Basics of qualitative research: Techniques and procedures for developing grounded theory. Thousand Oaks, CA: Sage.

Tramontana, Z. M. (2009). The connection between spirituality and recovery from bulimia nervosa. Dissertation Abstracts International: Section B: The Sciences and Engineering, 69(12-B), 7839.

Wasson, D. H., \& Jackson, M. (2004). An analysis of the role of overeaters anonymous in women's recovery from bulimia nervosa. Eating Disorders, 12, 337-356. http://dx.doi.org/10.1080/10640 260490521442

Watkins, J. A., Christie, C., \& Chally, P. (2006). Relationship between spiritual well-being and binge eating in college females. Eating and Weight Disorders, 11, 51-56. http://dx.doi.org/10.1007/ BF03327744

Zhang, K. C. (2013). What I look like: College women, body image, and spirituality. Journal of Religion and Health, 52, 1240-1252. http://dx.doi .org/10.1007/s10943-012-9566-0

Received September 13, 2017

Revision received January 19, 2018 Accepted January 24, 2018 